\title{
Alleviating Chilling Injury in Stored Pomegranate Using a Single Intermittent Warming Cycle: Fatty Acid and Polyamine Modifications
}

\author{
Leila Taghipour $\mathbb{D}^{1,2}$ Majid Rahemi, ${ }^{1}$ Pedram Assar, ${ }^{2}$ Asghar Ramezanian, ${ }^{1}$ \\ and Seyed Hossein Mirdehghan ${ }^{3}$ \\ ${ }^{1}$ Department of Horticultural Science, School of Agriculture, Shiraz University, P.O. Box: 71441-65186, Shiraz, Iran \\ ${ }^{2}$ Department of Horticultural Science, College of Agriculture, Jahrom University, P.O. Box: 74135-111, Jahrom, Iran \\ ${ }^{3}$ Department of Horticultural Science, College of Agriculture, Vali-Asr University of Rafsanjan, P.O. Box: 518, Kerman, Iran \\ Correspondence should be addressed to Leila Taghipour; 1_taghipoor@yahoo.com
}

Received 18 May 2021; Accepted 27 October 2021; Published 11 November 2021

Academic Editor: Alessio Allegra

Copyright (@ 2021 Leila Taghipour et al. This is an open access article distributed under the Creative Commons Attribution License, which permits unrestricted use, distribution, and reproduction in any medium, provided the original work is properly cited.

\begin{abstract}
Pomegranate is a perishable superfruit with important human health-promoting phytochemicals. The use of cold storage is inevitable for its long-term preservation. As pomegranate is sensitive to temperatures below $5^{\circ} \mathrm{C}$, it is therefore necessary and worthwhile to introduce a postharvest technique that is safe, applicable, and commercially acceptable to maintain the fruit quality under a cold storage condition. The efficacy of intermittent warming (IW) in the form of a single warming period $\left(1\right.$ day at $20^{\circ} \mathrm{C}$ with $70 \%$ relative humidity $(\mathrm{RH})$ before returning the treated fruit to storage) during the cold storage of 'Rabab-e-Neyriz' pomegranate (70 days at $2 \pm 0.5^{\circ} \mathrm{C}$ and $\left.90 \pm 5 \% \mathrm{RH}\right)$ was evaluated. To find the best treatment time, warming was performed at 4 temporary interruption points in storage (after 15, 25, 35, or 45 days of storage). For each interruption date, the treated fruit were compared to the controls twice, once immediately after treatment and once at the end of the storage period. It was founded that a single warming period at the right time during cold storage (before irreversible damage occurs) activated multiple mechanisms and physiological responses in pomegranate fruit peel that are significantly responsible for alleviating the severity of chilling damage to this commodity. In other words, warming on the 15th day was the most efficient treatment, resulting in better preservation of unsaturated fatty acids from peroxidation, lower malondialdehyde (MDA) production, and preservation of the unsaturated/saturated fatty acids (UFAs/SFAs) ratio (membrane integrity index) in the peel during storage and lower chilling injury symptoms. Moreover, the content of spermine ( $\mathrm{Spm}$ ) and putrescine (Put) (as important antioxidants acting as membrane safety agents) was significantly increased immediately after treatment, followed by a continuous increase in Spm and a higher level of Put compared to control until the end of storage.
\end{abstract}

\section{Introduction}

Nowadays, there is a worldwide and increasing notion that superfruits and their ingredients and extracts may have the ability to prevent diseases and/or be used as a cure for ailments. Pomegranate fruit (Punica granatum L.), known in many countries as the fruit of Eden [1], is a superfruit with excellent taste and great health benefits. Nearly 124 different phytochemicals can be found in pomegranate fruit; interestingly, not limited to the edible part of the fruit, which is likely to mediate in protective mechanisms against a wide range of oxidative and inflammatory human disorders, including cancer, type 2 diabetes, atherosclerosis and cardiovascular diseases [2].

Low-temperature storage is considered the most efficient way to preserve the postharvest quality of horticultural crops for an extended period of time. However, for some tropical or subtropical perishable products, such as pomegranate fruit, too long cold storage could result in a sequence of physiological 
disorders collectively known as chilling injury (CI), leading to significant loss of quality [3]. Therefore, finding safe, effective, and preferably non-chemical treatments to reduce postharvest losses during cold storage of pomegranate is both worthwhile and inevitable.

Intermittent warming (IW) is a potential environmentally friendly postharvest technique to alleviate chilling injury (CI) in cold-stored products and refers to the periodic exposure of fruit to warm temperatures at $20-27^{\circ} \mathrm{C}$ during storage [3-7]. The timing of treatment is critical [8], i.e., the initial interruption of cold storage must occur before the chilling damages become irreversible [5, 9]. In addition, it is essential to understand the ideal temperature, duration, and frequency that could be specific to each product and cultivar [9]. There are several hypotheses regarding IW's mechanism of action in alleviating chilling damage, e.g., an induced change in unsaturated fatty acids (UFAs) concentration which is considered involved in membrane safety at low temperatures. It was assumed that shifting the temperature from low to high and then from high to low would probably result in an increment of saturated fatty acids (SFAs) followed by desaturation leading to accumulation of UFAs and a greater degree of unsaturation. This change was suggested to affect membrane fluidity and result in increased tolerance to low temperatures $[6,7$, 10]. In addition, it has been reported that IW promotes polyamines (PAs) production in treated tissues [11]. It has been proposed that the mechanism of action for the alleviation of CI by exogenous PAs or treatments that enhance their endogenous values may be related to their ability to bind membranes and to have antioxidant activity [12] which mitigates changes in membrane fluidity and solute leakage [13] and results in membrane stability and delayed disintegration [14].

In contrast to achieving consensus on IW as a potential postharvest method, related research efforts in the new millennium have decreased. It is so important to keep in mind that there are challenges in choosing IW for commercial applications. It means that repeatedly increasing and decreasing the storage temperature is a slow and energy-intensive process. In addition, as an alternative, shifting the product from cold to warm rooms for several times is labor-intensive and requires the accessibility of specific spaces [3]. On the one hand, it is recommended that IW for crops with short shelf life, such as cucumbers, sweet peppers, and zucchini squash, be used more frequently $[7,11,15]$. On the other hand, if the warming is applied too frequently or for too long, an increased loss of quality may occur [16]. The authors believe it could be beneficial, more applicable, and commercially acceptable if only one cycle of IW is adequate to alleviate the incidence of CI and should be investigated for commercially important cultivars. In the other part of our research on the cold storage of 'Rabab-e-Neyriz' pomegranate fruit, the beneficial effect of one cycle of IW was revealed and related to the promotion of enzymatic and nonenzymatic antioxidant responses [17]. However, as stated by Biswas et al. [3], more research is needed to investigate the mechanisms by which IW alleviates CI, which can lead to alternative novel methods with similar advantages. To the best of our knowledge, more studies are required to evaluate the effects of IW on modifications in membrane fatty acids (FAs) and its fluidity and stability in cold-stored sensitive crops such as pomegranate fruit. Moreover, there is no literature available on the possible beneficial effect of IW via modification of endogenous PAs in pomegranate.

Pomegranate cv. 'Rabab-e-Neyriz' is a late ripening, exportable and commercial Iranian cultivar. The aim of the present research was to investigate the effects of a single warming period on modifications in FAs and PAs in fruit peel and its relationship with the mitigation of chilling damage to this product.

\section{Materials and Methods}

2.1. Plant Material, Experimental Design, and Treatments. Fully mature pomegranates cv. 'Rabab-e-Neyriz' were picked from a commercial orchard in Neyriz (Fars province, Iran). On the day of collection, the fruit were placed in vented plastic crates and transported to the laboratory in a cold room set to $5^{\circ} \mathrm{C}$. Upon arrival at the laboratory, fruit with defects were discarded and the remaining were stored at $2 \pm 0.5^{\circ} \mathrm{C}$ (chilling temperature) and $90 \pm 5 \% \mathrm{RH}$ for 70 days. IW was performed by exposure of the fruit to only one period of high temperature ( 1 day at $20^{\circ} \mathrm{C}$ with $70 \% \mathrm{RH}$ ) by shifting the fruit to a warm room during the storage period. To find the best treatment time, 4 temporary interruption points were dedicated to warming, i.e., $15 \mathrm{th}, 25 \mathrm{th}$, 35th, or $45 \mathrm{th}$ days of storage.

The experimental design was factorial based on a complete randomized design with three replications. It included 4 temporal points of interruption in storage (15th, 25th, 35 th, or 45 th days of storage) $\times 2$ levels of warming regime (warming and control) $\times 2$ levels of sampling time (immediately after treatment and at the end of storage). In other words, there was 4 distinct groups of fruit for each interruption day and 4 abbreviations were assigned: WI, WE, NI, and NE. The first letter explains the warming regime; whether the fruit were warmed $(\mathrm{W})$ or not $(\mathrm{N})$, and the second letter shows the sampling time; whether the samples were taken immediately after the warming regime (I) or at the end of the storage period (E). These groups included: Group A: fruit were removed from storage and immediately warmed by shifting to the warm room, and then sampled without delay (abbreviated to WI; as 15WI, 25WI, 35WI and 45WI). Group B: fruit immediately sampled after removal from storage without warming treatment (abbreviated to $\mathrm{NI}$; as $15 \mathrm{NI}, 25 \mathrm{NI}, 35 \mathrm{NI}$, and $45 \mathrm{NI}$ ). Group C: fruit were removed from storage and immediately shifted to the warm room for warming treatment, then were returned to cold storage and kept until the end of the storage period and sampled at the end (abbreviated to WE; as 15WE, 25WE, 35WE and 45WE). Group D: non-treated fruit without removal from storage, which were sampled at the end of cold storage (was abbreviated to NE; as $15 \mathrm{NE}, 25 \mathrm{NE}, 35 \mathrm{NE}$, and $45 \mathrm{NE}$ ). In other words, for each interruption date, groups $\mathrm{B}$ and $\mathrm{D}$ served as control for groups A and C, respectively. From this point of view, for each interruption date, the treated fruit were compared with the controls twice, immediately after treatment or at the end of the storage period. The content and composition of the FAs and the amount of PAs and malondialdehyde (MDA) in the peel samples 
were analyzed. In addition, chilling injury (CI) index in different time-treated fruit was evaluated at the end of the storage followed by a shelf life of 3 days and compared with control. Intact fruit were used for this purpose.

For the preparation of the sample, each husk was carefully cut in the equatorial zone and the peels were manually separated. Peel tissues from 10 fruit in each replicate were combined, frozen in liquid $\mathrm{N}_{2}$, and stored at $-80^{\circ} \mathrm{C}$ for later analytical determinations.

2.2. MDA Content and CI Index. The level of lipid peroxidation in the peel tissue was measured in terms of MDA content (a product of lipid peroxidation) determined by the thiobarbituric acid (TBA) reaction with minor modification of the method of Heath and Packer [18]. Briefly, $0.25 \mathrm{~g}$ of peel sample was homogenized in $5 \mathrm{~mL}$ of $0.1 \%$ trichloroacetic acid (TCA). The homogenated sample was centrifuged at
$10000 \times \mathrm{g}$ for $5 \mathrm{~min}$. To $250 \mu \mathrm{L}$ aliquot of the supernatant, $1 \mathrm{~mL} 20 \%$ TCA containing 0.5\% TBA was added. The mixture was heated at $95^{\circ} \mathrm{C}$ for $30 \mathrm{~min}$ and then quickly cooled in an ice bath. After being centrifuged at $10000 \times g$ for $10 \mathrm{~min}$, the absorbance of the supernatant was read at $532 \mathrm{~nm}$ and the value for the nonspecific absorption at $600 \mathrm{~nm}$ was subtracted. The concentration of MDA was calculated using its extinction coefficient $(\varepsilon)$ of $155 \mathrm{mM}^{-1} \mathrm{~cm}^{-1}$ reported as $\mu \mathrm{mol}$ per $\mathrm{g}$ of peel fresh weight.

The CI index was assessed separately in each fruit with a 4-point hedonic scale based on the proportion of the peel surface impacted by CI symptoms (dehydration, browning, and pitting) [19]: 0 (no symptoms), 1 (1-25\% of damaged area), 2 (26-50\% of damaged area) and 3 ( $>50 \%$ of damaged area). The results were expressed as the mean $\pm \mathrm{SD}$ of $\mathrm{CI}$ calculated using the following formula:

$\mathrm{CI}=\sum$ (value of hedonic scale $\times$ number of fruit with the corresponding scale number $) /(4 \times$ total number of fruit in the sample $)$.

2.3. Fatty Acids (FAs) Quantification. Total lipids were extracted according to the method of Rui et al. [20]. A gas chromatograph (GC, HP-model 6890) equipped with a flame ionization detector was used to separate and quantify fatty acids according to Mirdehghan et al. [21]. At first, two g of skin was homogenised in $10 \mathrm{~mL}$ of chloroform:methanol: $0.1 \mathrm{~N} \mathrm{HCl}(200: 100: 1)$. Then, $10 \mathrm{~mL}$ of $0.1 \mathrm{~N}$ $\mathrm{HCl}$ was added before centrifugation at $4000 \times g$ for $10 \mathrm{~min}$. It was allowed to the organic phase to be dried. By adding $1 \mathrm{~mL}$ of boron trifluoride/methanol at boiling temperature for $10 \mathrm{~min}$, fatty acid methylation was done. Using hexane, methylated fatty acids were extracted and then allowed to be dried and redissolved in $200 \mu \mathrm{L}$ chloroform before injection. For fatty acid separation and quantification, a HP-Innowax polyethylene glycol capillary column $(30 \mathrm{~m} \times 250 \mu \mathrm{m} \times 25 \mu \mathrm{m})$ and a gradient of temperature (initially $120^{\circ} \mathrm{C}$ for $2 \mathrm{~min}$ and then a rate at $4{ }^{\circ} \mathrm{C} / \mathrm{min}$ to $190^{\circ} \mathrm{C}$ which was held for $5 \mathrm{~min}$, and final rate at $4^{\circ} \mathrm{C} / \mathrm{min}$ to $242^{\circ} \mathrm{C}$ ) were used. Fatty acids were identified and quantified by comparing retention times and peak areas with authentic standards (Sigma-Aldrich, USA). Results were expressed as $\mathrm{mg} 100 \mathrm{~g}^{-1}$ fresh weight.

2.4. Polyamines (PAs) Quantification. Sample preparation and HPLC analysis of PAs was performed according to Mirdehghan et al. [21] with some modifications. For each replicate, $1 \mathrm{~g}$ of fresh tissue was homogenized with $10 \mathrm{~mL}$ of $5 \%$ cold perchloric acid. The homogenate was then centrifuged for $30 \mathrm{~min}$ at $20000 \times g$. The resulted supernatant was filtered through a $0.45 \mu \mathrm{m}$ filter (Millipore) and used to determine free PAs by benzoylation, and derivatives analysed by HPLC (UnicamCrystal-200, UK). A $10 \mu \mathrm{L}$ of filtered supernatant was used for this purpose. The elution system consisted of $\mathrm{MeOH} / \mathrm{H}_{2} \mathrm{O}(64: 36)$ solvent, running isocrati0- cally with a flow rate of $0.8 \mathrm{~mL} \mathrm{~min}^{-1}$ through a reversedphase column (LiChroCart 250-4.5 $\mu \mathrm{m}$ ) and detection was based on UV absorbance at $254 \mathrm{~nm}$. PAs were identified and quantified by comparing retention times and peak areas with authentic standards (Sigma-Aldrich, USA). Results were expressed as nmol g${ }^{-1}$ fresh weight.

2.5. Statistical Analysis. All data were subjected to two-way analysis of variance (ANOVA) performed with the SAS 9.1.3 service pack 4 software (SAS Institute, Cary, NC, USA), and the means were separated by the least significant difference (LSD) test at $\mathrm{P} \leq 0.05$.

\section{Results}

3.1. MDA Content and CI Index. Mean comparisons showed that the MDA content increased significantly during storage. Generally, the warming resulted in a significantly lower MDA content compared to untreated fruit. Moreover, the mean value at the end of storage was significantly higher than the time of interruption (Table 1).

The amount of MDA in the peel of control fruit was nearly similar to the harvesting time until the 25th day of cold storage, and there was no significant difference between the cold-stored fruit sampled on the 15th and 25th days of storage. Subsequently, there was a significant increasing trend along with storage time. Fruit warming at 15th and 45th days instantly reduced the MDA content of the peel compared to the controls (Table 2). On the other hand, at the end of the storage period, the fruit treated at interruption dates had significantly lower MDA (Table 2) and CI index (Table 3) compared to the controls with the lowest levels recorded for the fruit treated on the 15th and 25th days. 


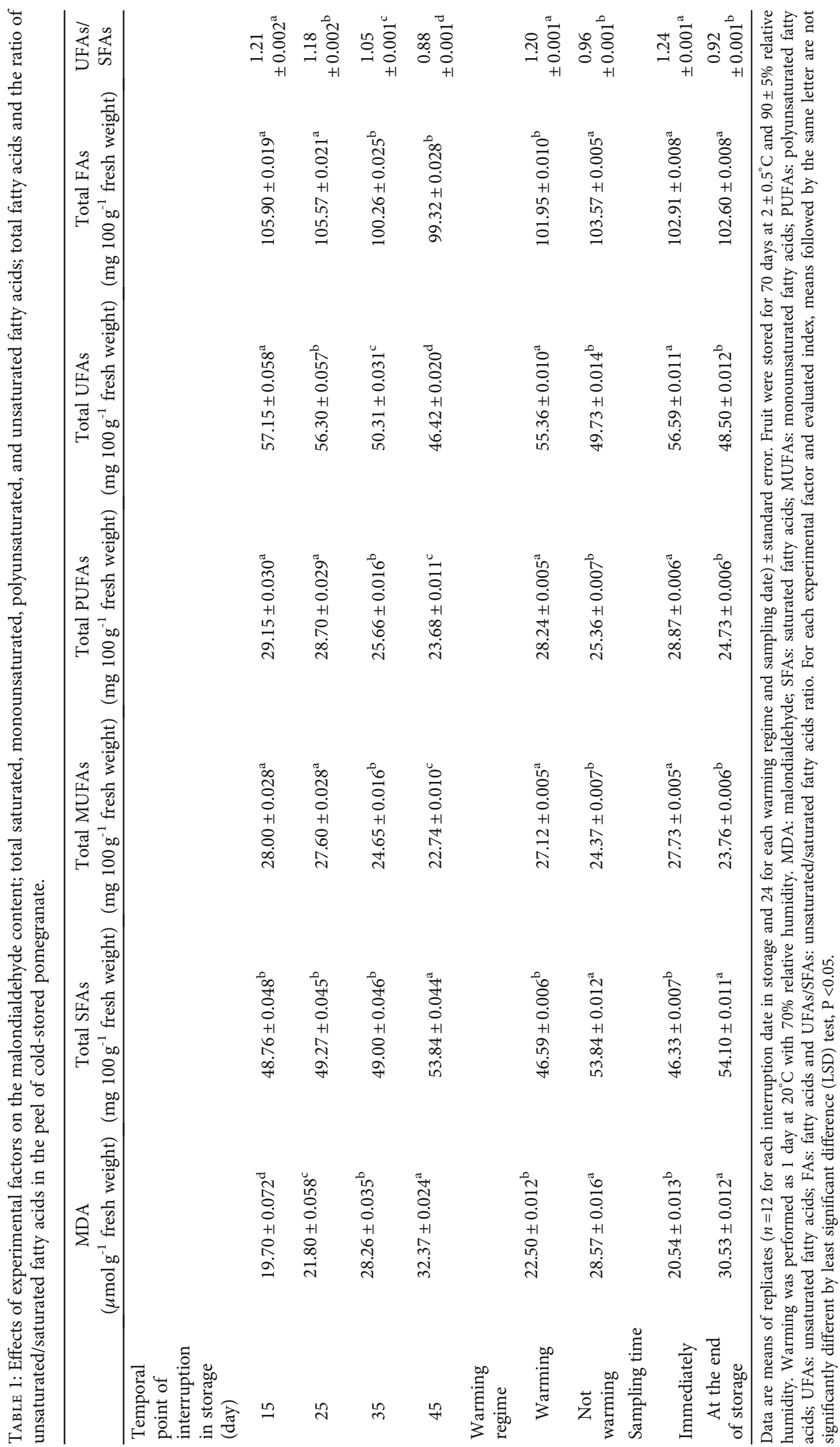




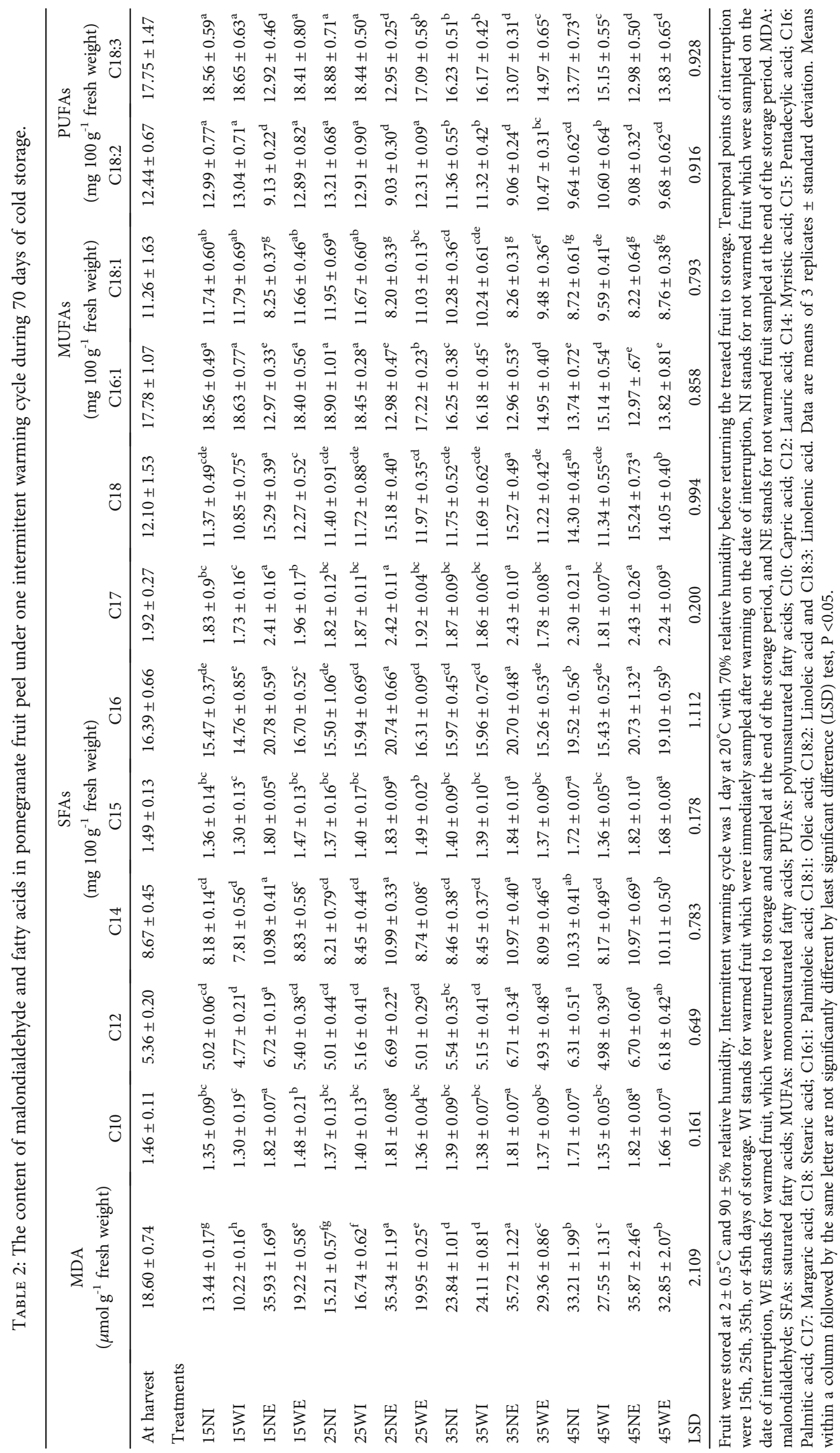


TABLE 3: Differences in chilling injury index between control and intermittently warmed fruit after 70 days of cold storage and additional 3 days shelf life at $20^{\circ} \mathrm{C}$.

\begin{tabular}{|c|c|c|c|c|c|}
\hline & \multicolumn{5}{|c|}{ Warming day during storage } \\
\hline & $\mathrm{C}$ & 15 & 25 & 35 & 45 \\
\hline CI index & $0.48 \pm 0.04^{\mathrm{a}}$ & $0.18 \pm 0.04^{\mathrm{d}}$ & $0.21 \pm 0.03^{\mathrm{d}}$ & $0.27 \pm 0.03^{\mathrm{c}}$ & $0.33 \pm 0.02^{\mathrm{b}}$ \\
\hline
\end{tabular}

\subsection{FAs Modifications}

3.2.1. SFAs, Mono and Poly UFAs. The following FAs have been identified and quantified in the peel samples (Figure 1(a) and Table 2): capric acid (C10), lauric acid (C12), myristic acid (C14), pentadecylic acid (C15), palmitic acid (C16), margaric acid (C17) and stearic acid (C18) as saturated (SFAs); palmitoleic acid (C16:1) and oleic acid (C18:1) as monounsaturated (MUFAs); and linoleic acid $(\mathrm{C} 18: 2)$ and linolenic acid (C18:3) as polyunsaturated (PUFAs) ones.

3.2.2. Total SFAs (Membrane Saturation Index). The fruit had significantly higher total SFAs at the last interruption time (45th day) of storage than other times. In addition, statistically lower mean values were recorded for the warmed fruit and those sampled at the interruption dates compared to the untreated fruit and those sampled at the end of the experiment, respectively (Table 1 ).

Up to 35 days of cold storage, the total SFAs did not change. Subsequently, a significant increasing trend was detected, with the highest amount recorded at the end of storage. The instant effect of warming on the membrane saturation index was detected only on the fruit treated on the 45th day, leading to a statistical decrease in the index compared to the control. However, treating the fruit at any time of interruption in storage resulted in significantly lower total SFAs recorded at the end of the experiment compared to the controls (Figure 2(a)).

3.2.3. Total MUFAs, PUFAs, and UFAs (Membrane Unsaturation Index). The results showed a significant decrease in all unsaturation indices during cold storage. On the other hand, the mean values of the warmed fruit and fruit immediately sampled at interruption dates were significantly higher than those of the untreated fruit and fruit sampled at the end of the cold storage period, respectively (Table 1).

Total MUFAs, PUFAs, and therefore membrane unsaturation index increased to the 25th day of storage, even more than the harvesting time. Subsequently, a significant decreasing trend was identified until the end of storage. By warming the fruit on the 45th day of cold storage, all unsaturation indices were increased significantly, even though at the end of the experiment, the fruit treated at any time during the storage period had significantly higher levels of MUFAs, PUFAs and UFAs than the controls (Figures 2(b), 2(c) and 2(d)).
3.2.4. Total FAs. Mean comparisons showed that the total FAs content at the first and second interruption dates was significantly higher than at the later dates, with no significant difference between the fruit sampled at the 15th and 25th or 35th and 45th days. Generally, the treated fruit had significantly lower total FAs than the untreated fruit, and there was no significant difference between the fruit sampled at interruption dates or at the end of the experiment (Table 1).

On the one hand, the total FAs increased to the 25th day of storage, even more than the harvesting time. On the other hand, the index subsequently decreased significantly, without a statistical difference between the fruit sampled on the 35th day and later. Fruit warming at interruption dates had no immediate impact on total FAs content except on the 45th day, which resulted in a significant decrease in the index compared to the control. Moreover, only fruit treated during the first month had higher total FAs compared to controls at the end of the storage period. From this point of view, there was a significant difference between the fruit treated on the 15th day and the control fruit at the end of the experiment (Figure 2(e)).

3.2.5. UFAs/SFAs Ratio (Membrane Integrity Index). It was observed a significant decreasing trend in the UFAs/SFAs ratio with progress in the storage period. In addition, a significantly higher mean value was found for treated fruit and fruit immediately sampled at interruption dates compared to untreated fruit and those sampled at the end of the storage period (Table 1).

The membrane integrity index improved to the 25th day of storage, even better than the harvesting time. Subsequently, a significant decreasing trend was detected up to the end of storage. On the other hand, at the end of the storage period, all fruit treated at interruption dates had a statistically higher UFAs/SFAs ratio compared to controls (Figure 2(f)).

3.3. PAs Modifications. The three main polyamines, putrescine (Put), spermidine (Spd), and spermine (Spm) in their free forms, were identified and quantified in pomegranate peel (Figure 1(b)).

3.3.1. Put Content. Mean comparisons showed that the advancement in storage from the 25th day to the end was followed by a significant decrease in the concentration of Put. Treated fruit had significantly higher content of Put than untreated fruit. In addition, the amount of Put was 


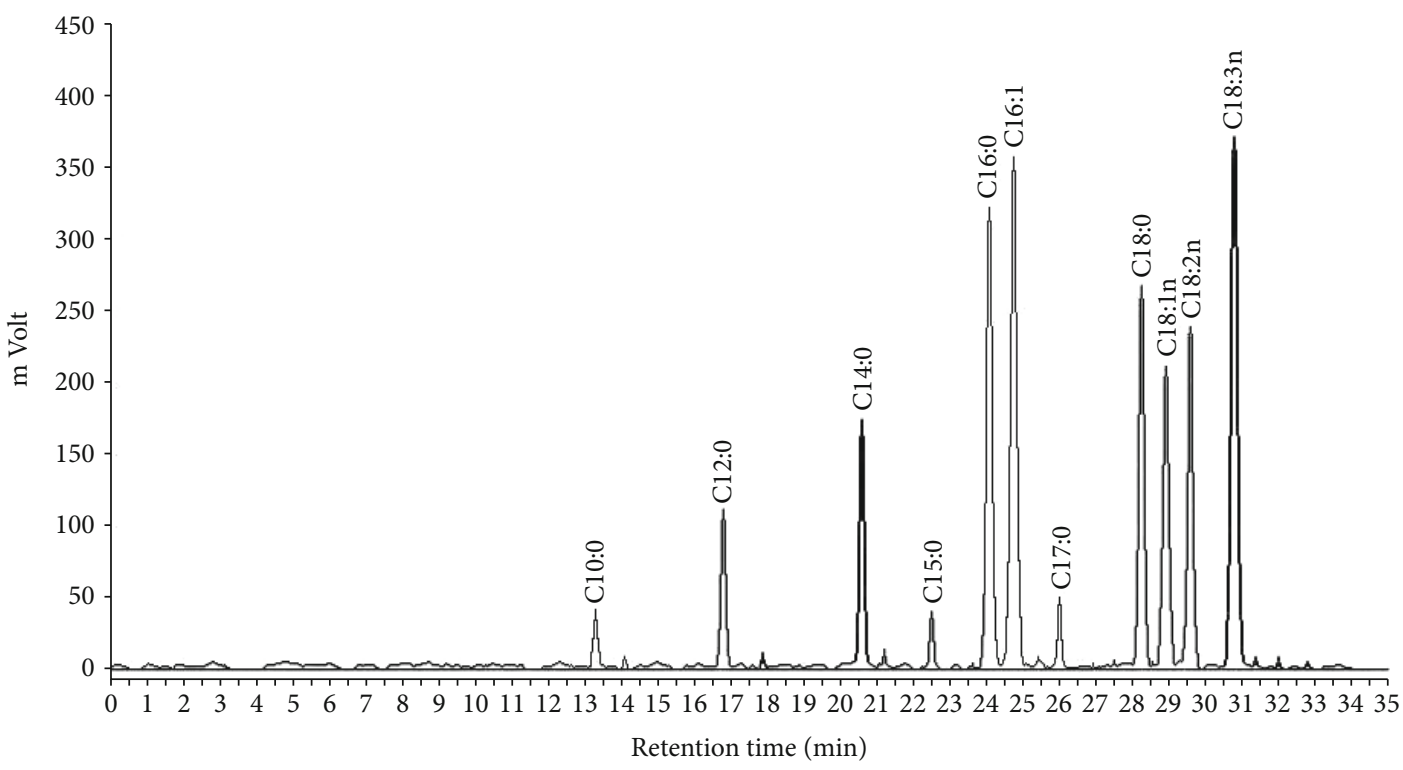

(a)

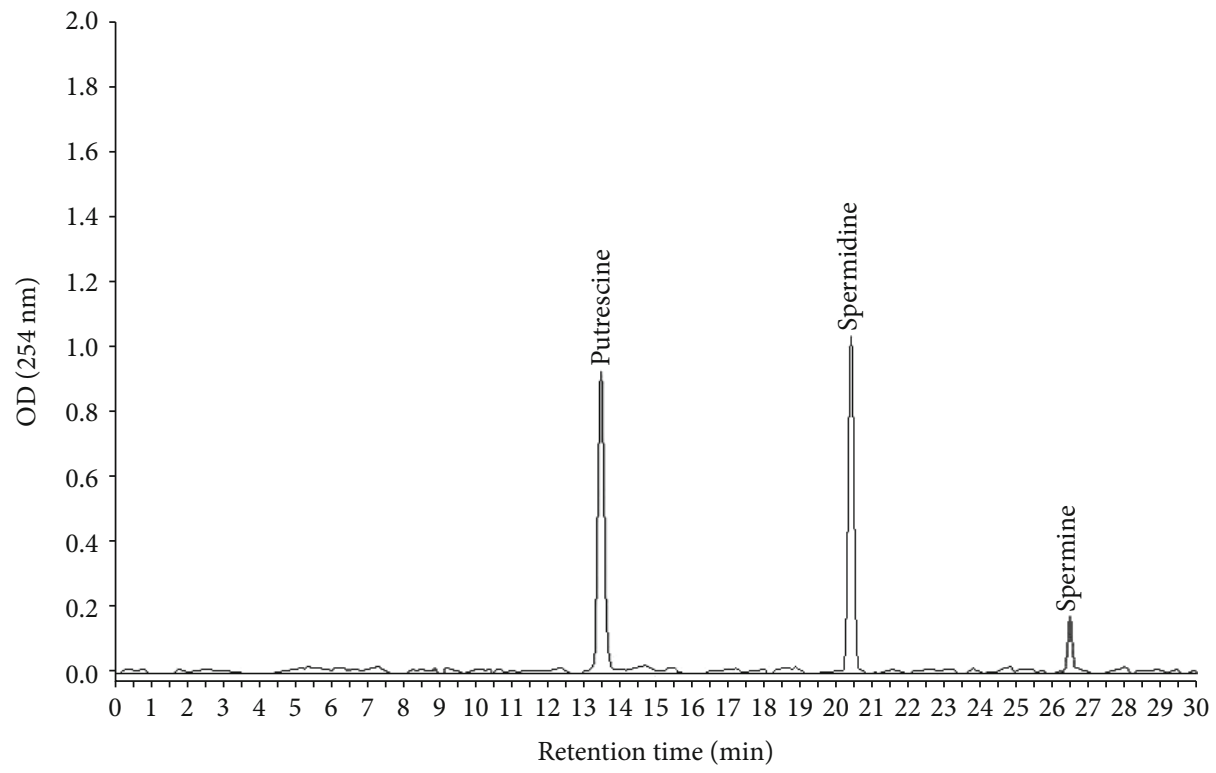

(b)

FIgURE 1: GC chromatogram of Fatty Acids (a), and HPLC chromatogram of Polyamines (b) in pomegranate peel. C10: Capric acid; C12: Lauric acid; C14: Myristic acid; C15: Pentadecylic acid; C16: Palmitic acid; C17: Margaric acid; C18: Stearic acid; C16:1: Palmitoleic acid; C18:1: Oleic acid; C18:2: Linoleic acid and C18:3 Linolenic acid.

statistically lower at the end of storage than during storage (Table 4).

During cold storage, the content of Put decreased significantly and continuously until the 45th day, with no statistical difference between the 45th and 70th days. Warming at interruption dates resulted in an immediate increase and higher final contents compared to controls, except for the fruit treated on the 45th day which had the final amount of Put the same as the control (Figure 3(a)).

3.3.2. Spd Content. According to the mean comparison, the concentration of Spd increased significantly as the storage time progressed. In addition, the treated fruit had statistically higher levels of Spd than the untreated fruit and the amount of Spd at the end of storage was significantly higher than what was recorded during that period (Table 4).

Statistically, the internal concentration of Spd was continuously increased until the 35th day of cold storage, with no differences between the fruit sampled on the 35th and 45th days. Subsequently, a significant decrease in Spd content was recorded for the last 25 days of cold storage. Warming at all interruption dates, except for the 15th day, resulted in a significant instant increase and a statistically higher final value of Spd at the end of storage compared to the control fruit (Figure 3(b)). 


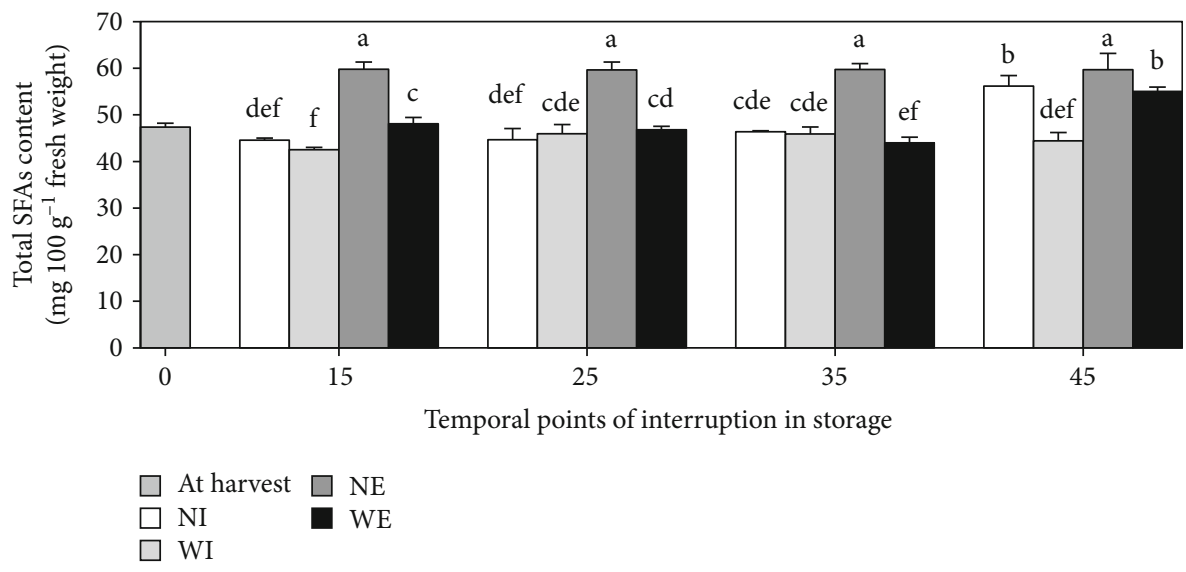

(a)

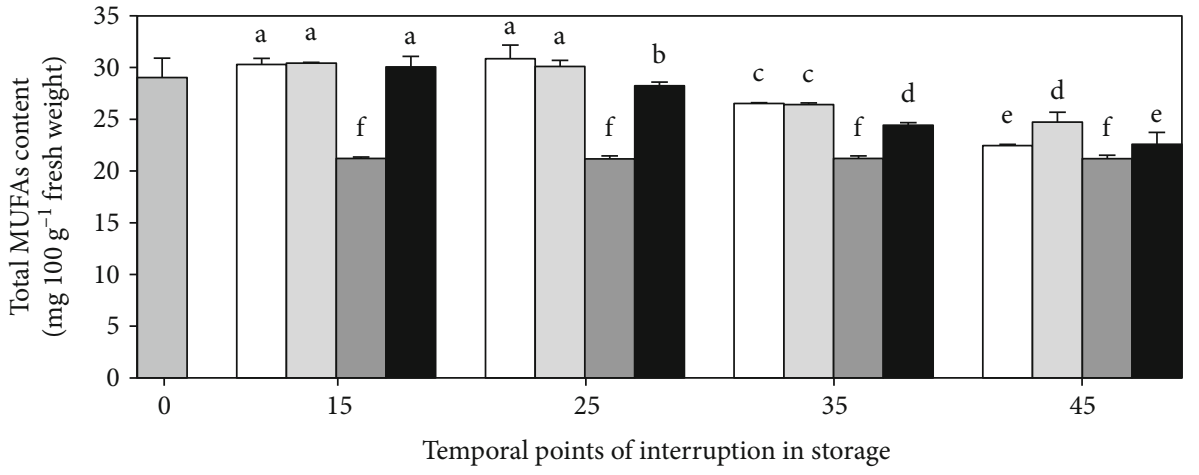

$\square$ At harvest $\square \mathrm{NE}$

$\square \mathrm{NI} \quad \mathrm{WE}$

$\square$ WI

(b)

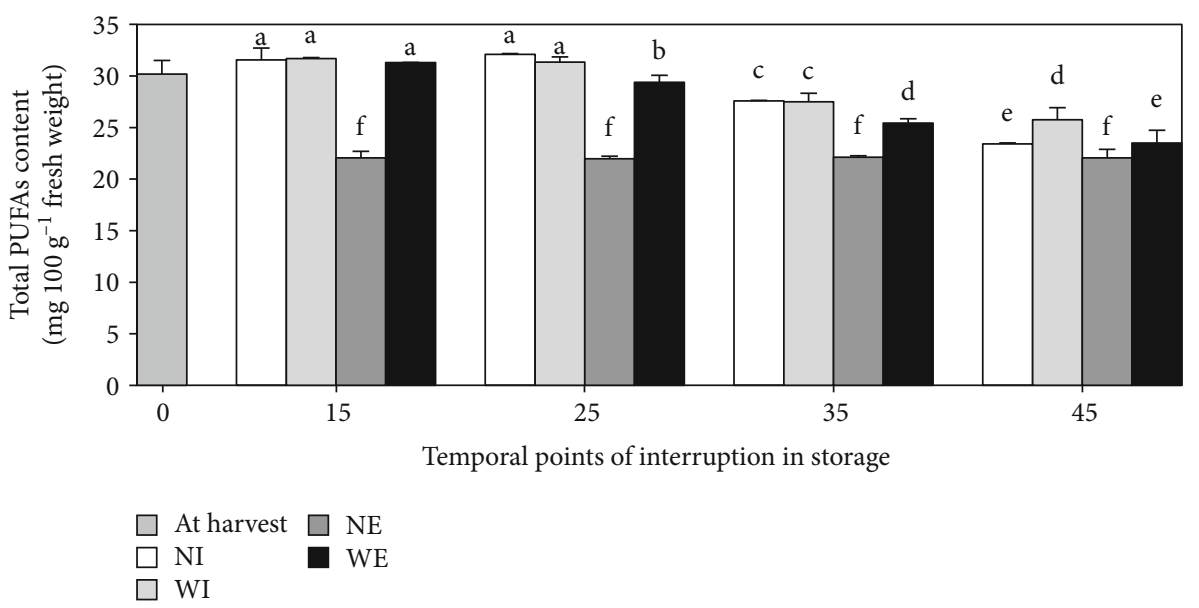

(c)

Figure 2: Continued. 


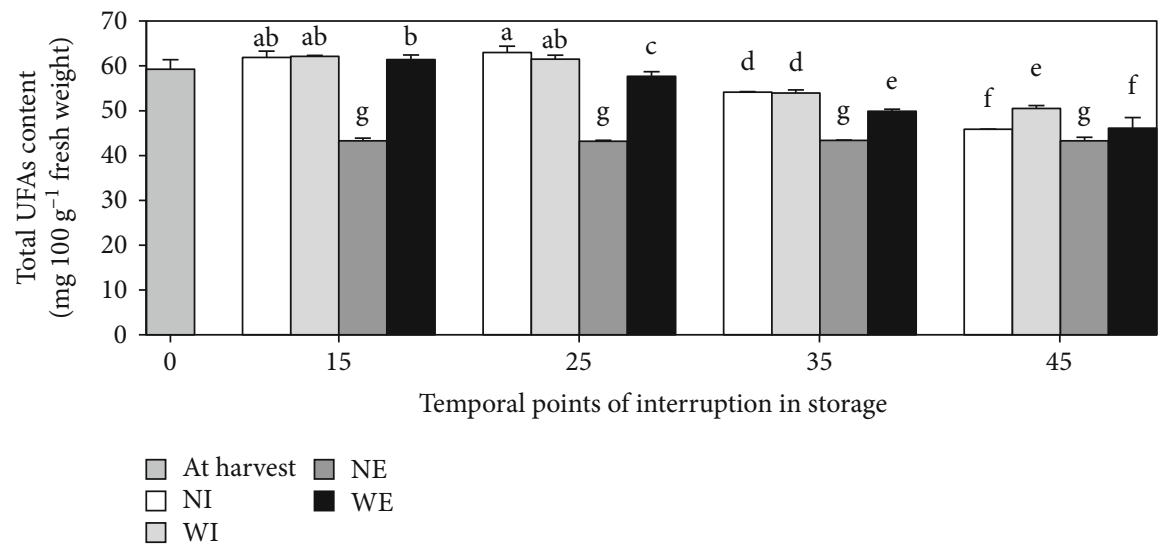

(d)
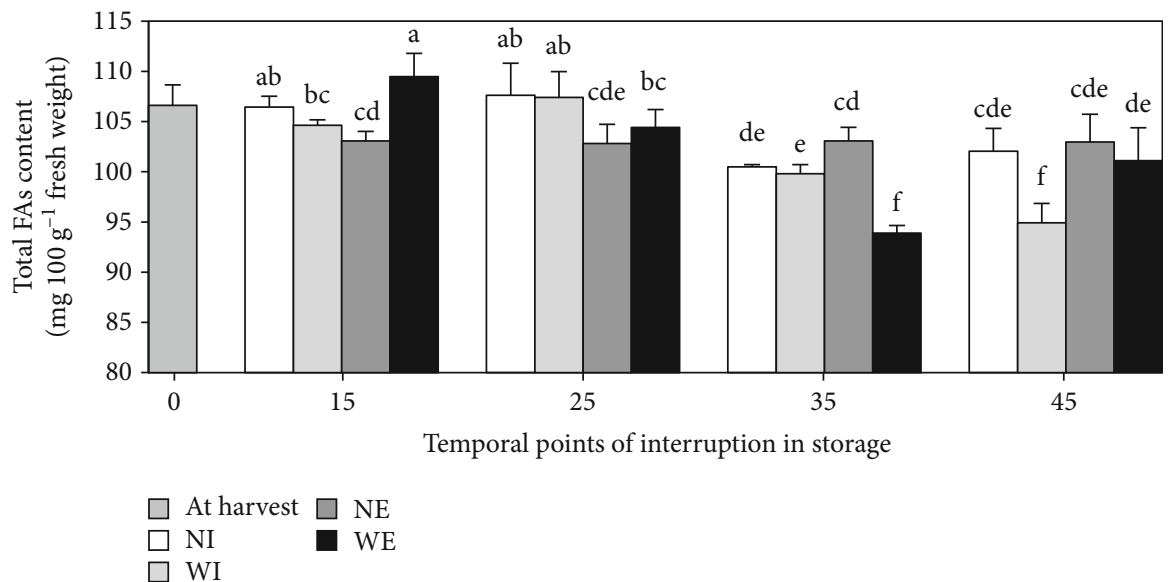

(e)
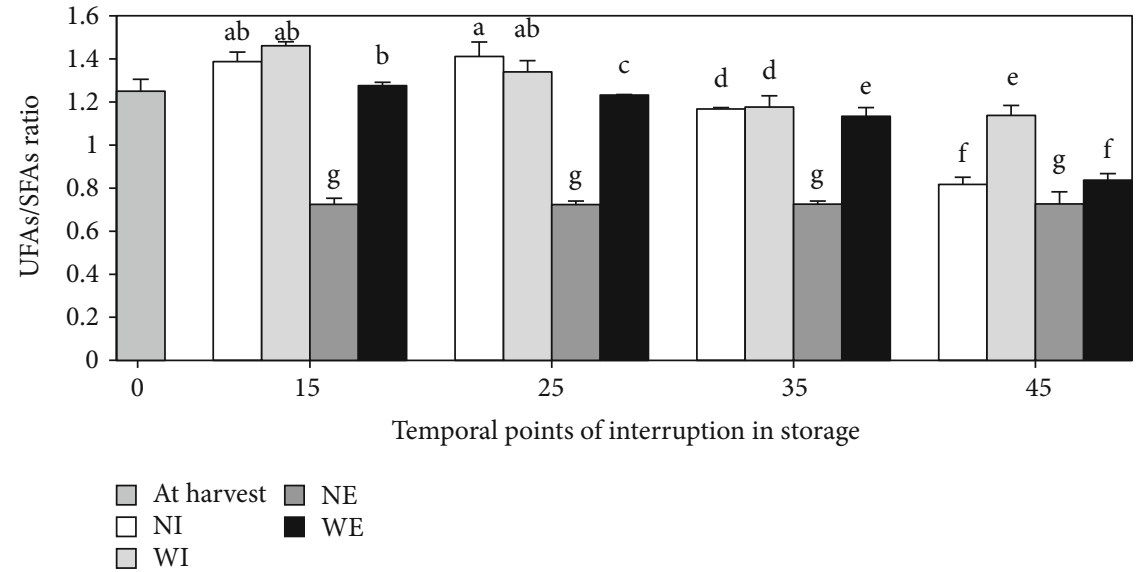

(f)

Figure 2: Modifications in the total content of saturated (a), monounsaturated (b), polyunsaturated (c), and unsaturated (d) fatty acids, total fatty acids (e), and unsaturated/saturated fatty acids ratio (f) in pomegranate fruit peel during 70 days storage (at $2 \pm 0.5^{\circ} \mathrm{C}$ and $90 \pm 5 \% \mathrm{RH}$ ). Intermittent warming was conducted in the form of a single warming period ( 1 day at $20^{\circ} \mathrm{C}$ with $\left.70 \% \mathrm{RH}\right)$ before returning the treated fruit to storage. Temporal points of interruption were 15 th, 25 th, 35 th, or 45 th days of storage. WI stands for warmed fruit which were immediately sampled after warming on the date of interruption, NI stands for not warmed fruit which were sampled on the date of interruption, WE stands for warmed fruit, which were returned to storage and sampled at the end of the storage period, and NE stands for not warmed fruit sampled at the end of the storage period. Data are means of 3 replicates \pm SD. All statistical differences (by LSD test, $\mathrm{P} \leq 0.05)$ throughout the storage period are shown in different letters. 
TABLE 4: Effects of experimental factors on the content of polyamines (PAs) in the peel of cold-stored pomegranate.

\begin{tabular}{|c|c|c|c|}
\hline & $\begin{array}{c}\text { Put } \\
\left(\mathrm{nmolg}^{-1} \text { fresh weight }\right)\end{array}$ & $\begin{array}{c}\text { Spd } \\
\left(\mathrm{nmol} \mathrm{g}^{-1} \text { fresh weight) }\right.\end{array}$ & $\begin{array}{c}\text { Spm } \\
\left(\mathrm{nmolg}^{-1} \text { fresh weight }\right)\end{array}$ \\
\hline \multicolumn{4}{|c|}{ Temporal point of interruption in storage (day) } \\
\hline 15 & $269.50 \pm 0.84^{\mathrm{a}}$ & $221.00 \pm 0.34^{\mathrm{d}}$ & $26.65 \pm 0.04^{\mathrm{b}}$ \\
\hline 25 & $248.38 \pm 0.79^{\mathrm{a}}$ & $295.00 \pm 0.38^{\mathrm{c}}$ & $29.94 \pm 0.05^{\mathrm{a}}$ \\
\hline 35 & $194.50 \pm 0.51^{\mathrm{b}}$ & $346.00 \pm 0.45^{\mathrm{b}}$ & $19.25 \pm 0.03^{\mathrm{c}}$ \\
\hline 45 & $122.33 \pm 0.22^{\mathrm{c}}$ & $374.00 \pm 0.53^{\mathrm{a}}$ & $17.06 \pm 0.03^{\mathrm{d}}$ \\
\hline \multicolumn{4}{|l|}{ Warming regime } \\
\hline Warming & $263.56 \pm 0.16^{\mathrm{a}}$ & $350.30 \pm 0.16^{\mathrm{a}}$ & $26.57 \pm 0.01^{\mathrm{a}}$ \\
\hline Not warming & $153.79 \pm 0.16^{\mathrm{b}}$ & $267.76 \pm 0.09^{\mathrm{b}}$ & $19.88 \pm 0.01^{\mathrm{b}}$ \\
\hline \multicolumn{4}{|l|}{ Sampling time } \\
\hline Immediately & $260.38 \pm 0.18^{\mathrm{a}}$ & $293.79 \pm 0.16^{\mathrm{b}}$ & $22.19 \pm 0.01^{\mathrm{b}}$ \\
\hline At the end of storage & $156.98 \pm 0.14^{\mathrm{b}}$ & $324.25 \pm 0.13^{\mathrm{a}}$ & $24.26 \pm 0.01^{\mathrm{a}}$ \\
\hline
\end{tabular}

Data are means of replicates ( $n=12$ for interruption date in storage and 24 for warming regime and sampling date) \pm standard error. Fruits were stored for 70 days at $2 \pm 0.5^{\circ} \mathrm{C}$ and $90 \pm 5 \%$ relative humidity. Warming was performed as 1 day at $20^{\circ} \mathrm{C}$ with $70 \%$ relative humidity. Put: putrescine; Spd: spermidine; Spm: spermine. For each experimental factor and evaluated index, means followed by the same letter are not significantly different by the least significant difference (LSD) test, $P<0.05$.

3.3.3. Spm Content. Mean comparisons showed that more Spm level was detected in the fruit sampled on the 25th day of storage and those sampled on the 15th, 35th, and 45 th days were at the next position, respectively, and all differences were significant. Generally, the warming resulted in statistically higher Spm content and the value detected at the end of storage was significantly higher than that measured at the time of interruption (Table 4).

Modifications in the concentration of Spm during storage could be categorized into three different parts: an increase up to the 25th day, subsequent decrease up to the 45th day, and then increase up to the end of storage. Most of the differences were almost significant. Warming during storage immediately led to a significant increase in the content of Spm. Although only fruits treated on the 15th and 25th days had statistically more Spm than controls at the end of the storage period, the other time-treated fruit were the same as the controls. The fruit sampled on the 25th day had a statistically higher endogenous content of Spm compared to other different time-sampled fruit and had a significantly higher instant increase and final content of Spm in response to treatment than the fruit treated at the other interruption dates (Figure 3(c)).

\section{Discussion}

4.1. MDA Content and CI Index. The investigation of changes in the MDA content (Table 2) revealed that lipid peroxidation increased after one month of chilling stress. Examining the physiological changes and the incidence of chilling injury in the same storage condition as we did earlier, Taghipour et al. [8] showed that pomegranate fruit cv. Rabab-e-Neyriz could be stored in cold temperature without significant CI for up to 30 days. From this point of view, our finding was consistent with them. At the end of the storage period, all different time-treated fruit had a significantly lower MDA and CI index compared to the controls, with the lowest levels recorded for the fruit treated on the 15 th and 25th days (Tables 2 and 3). In accordance with our finding, Taghipour et al. [8] suggested that the warming should be carried out during the first month of cold storage, predicting it with the possible desired effect of extending the shelf life of this commercial cultivar. These data suggested IW's prominent efficacy in alleviating the incidence of pomegranate CI at low temperatures, which part of the related mechanisms are discussed based on our findings in the following parts of discussion.

4.2. FAs Modifications. It has been accepted that chillingresistant subtropical and tropical horticultural crops have greater levels of UFAs and UFAs/SFAs ratio in cell membrane lipids $[22,23]$. Higher levels of UFAs lead to higher membrane fluidity, identified as part of low-temperature tolerance mechanisms [24-26]. It means that the intensity of the lipid phase shift from flexible liquid crystalline to solid gel is lower in the membrane with greater fluidity, thus maintaining the membrane permeability and greater tolerance to low temperatures $[5,25]$. For example, it has been indicated that chilling-tolerant cultivars of loquat fruit have a greater linoleic (C18:2) and linolenic (C18:3) acid content and lower palmitic (C16) and stearic acid (C18) concentrations, resulting in a greater UFAs/SFAs ratio [27]. On the one hand, higher activity of phospholipase D (PLD) and lipoxygenase (LOX) enzymes could be liable for UFAs degradation at chilling temperatures leading to decreased cell membrane integrity and increased adverse effects of CI [28]. On the other hand, non-enzymatic oxidation of UFAs by reactive oxygen species (ROS) associated with MDA production could result in reduced membrane integrity and increased adverse effects of CI [29]. The integrity of the membrane plays a crucial role in fruit pericarp browning as one of the CI symptoms [29].

Results indicated that the values of all SFAs (Table 2) and the membrane saturation index (Figure 2(a)) of the fruit sampled at any time of interruption up to the 35th day of cold storage were statistically the same and, in most cases, 

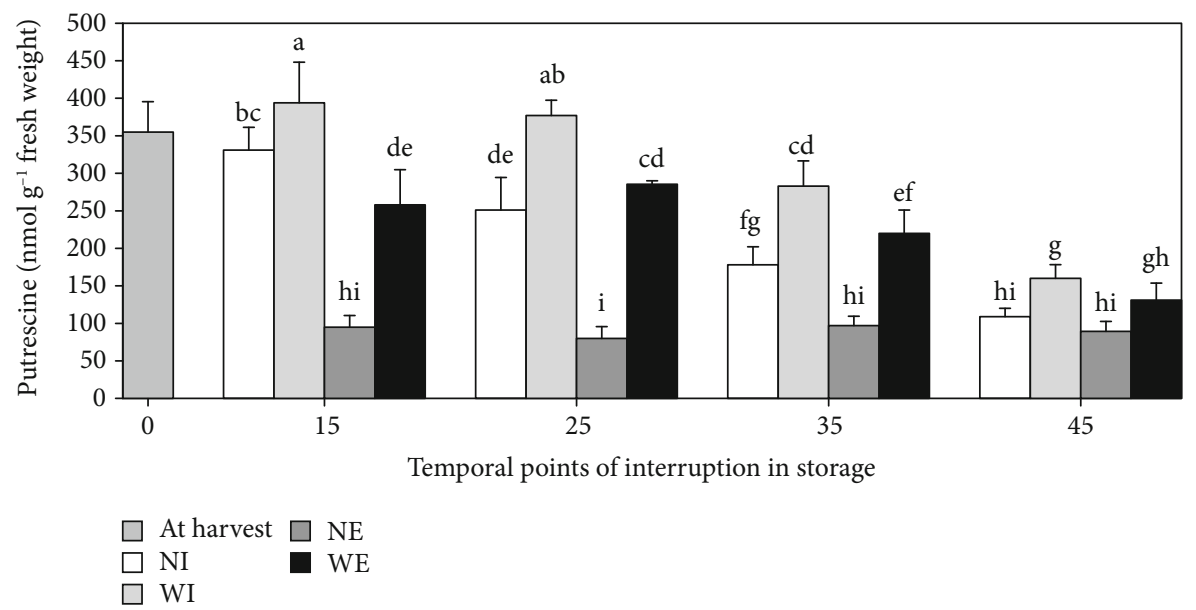

(a)
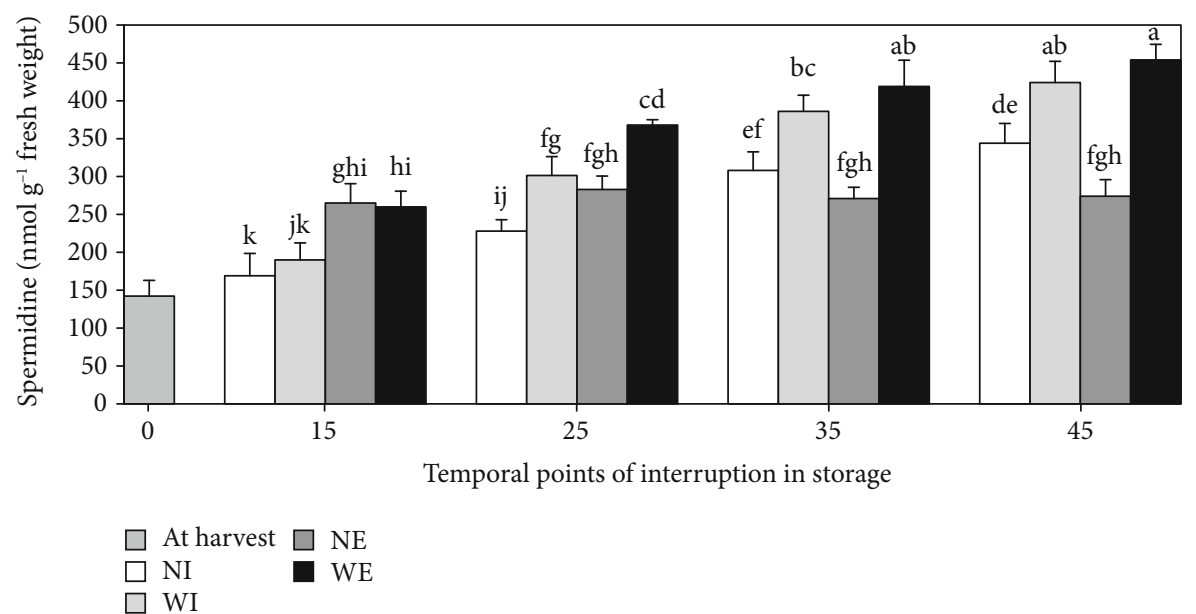

$\square$ WI

(b)

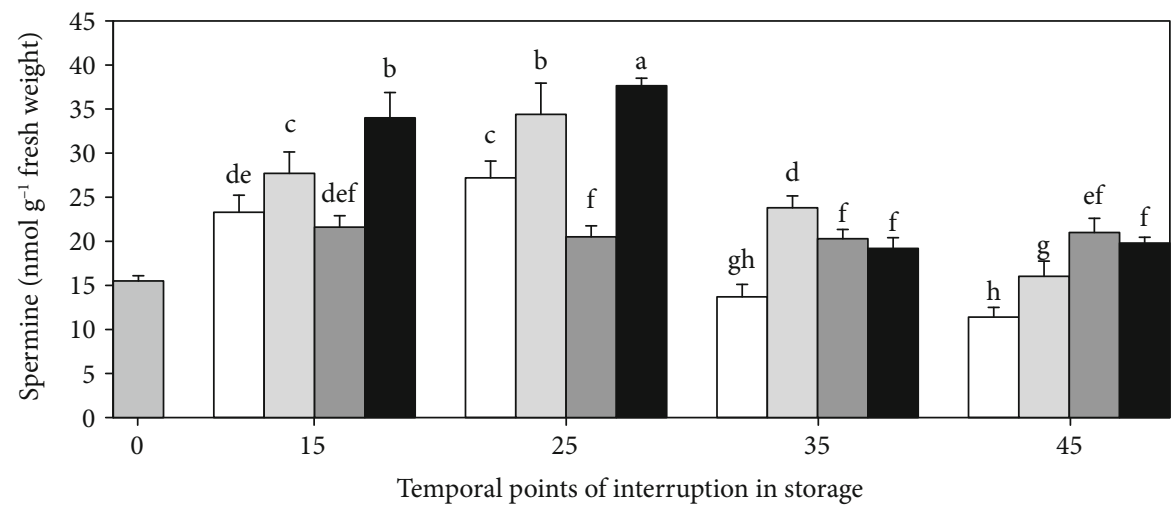

$\square$ At harvest $\square$ NE
$\square$ NI
$\square$ WI

(c)

Figure 3: Modifications in the content of putrescine (a), spermidine (b), and spermine (c) in pomegranate fruit peel during 70 days storage (at $2 \pm 0.5^{\circ} \mathrm{C}$ and $90 \pm 5 \% \mathrm{RH}$ ). Intermittent warming was conducted in the form of a single warming period $\left(1 \mathrm{day}\right.$ at $20^{\circ} \mathrm{C}$ with $70 \% \mathrm{RH}$ ) before returning the treated fruit to storage. Temporal points of interruption were 15th, 25th, 35th, or 45th days of storage. WI stands for warmed fruit which were immediately sampled after warming on the date of interruption, NI stands for not warmed fruit which were sampled on the date of interruption, WE stands for warmed fruit, which were returned to storage and sampled at the end of the storage period, and NE stands for not warmed fruit sampled at the end of the storage period. Data are means of 3 replicates \pm SD. All statistical differences (by LSD test, $\mathrm{P} \leq 0.05$ ) throughout the storage period are shown in different letters. 
even lower than the harvest time value. Afterwards, as shown in Table 2, there was a significant increasing trend for all SFAs up to the 45th day of storage, which was continued only for palmitic acid during the last 25 days of the cold storage period. On the other hand, all MUFAs and PUFAs have risen up to the 25th day of storage, even more than the harvest time. However, a declining trend with significant differences between the fruit sampled on the 25th, 35th, and 45th days was subsequently founded, the latter having statistically the same contents of all MUFAs and PUFAs as detected at the end of the storage period. These data indicated that the fruit had significant changes in peel fatty acids following the expected adverse effects of CI on cell membrane integrity after approximately 1 month of cold storage. The stability of the membrane saturation index up to the 35 th day (Figure 2(a)) and the stability of the unsaturation index up to the 25th day (Figure 2(d)), without an increase in the MDA level during the first month of storage (Table 2), could be associated with low-temperature fruit acclimatization to prevent chilling injury. This is similar to what was reported by Antunes and Sfakiotakis [30], as a major increase in the UFAs/SFAs ratio during the first days of kiwifruit storage as a response to tissue adaptation to new stress storage conditions.

Transferring cold-stored fruit to an elevated temperature and returning it to the previous temperature has been reported to regulate and readjust the metabolic processes leading to improved UFAs synthesis. In other words, the warming appears to result in an increase in the synthesis and elongation of the SFAs chains, which can act as a substrate for UFAs synthesis and increase the degree of unsaturation of the cell membrane after returning to cold temperature $[6,7,10]$. It has been noted, for instance, that peach and cucumber warming caused an increase in $\mathrm{C} 18$, while subsequent exposure to cold temperature resulted in an increase in C18:1, C18:2 and C18:3. It was suggested that IW could result in the enhanced amount of C18 as a prerequisite for UFAs synthesis, thus improving the degree of unsaturation in membrane lipids [6]. Rapid changes in membrane lipids with altered temperatures have also been reported in soybean roots. As the temperature was raised, $\mathrm{C} 16$ and $\mathrm{C} 18$ increased, but $\mathrm{C} 18: 1, \mathrm{C} 18: 2$, and $\mathrm{C} 18: 3$ decreased in plasma membranes and mitochondrial membrane; the reverse trend happened as the temperature was lowered [31].

Moreover, the data collected at the end of storage showed that fruit treated for up to 35 days of cold storage had significantly higher amounts of all MUFAs and PUFAs (Table 2) and, as a result, higher levels of total MUFAs, PUFAs and UFAs (Figures 2(b), 2(c) and 2(d)) compared to control. Notably, in the fruit treated on the 15th day, these indices remained unchanged until the end of the experiment. Indeed, the fruit treated on the 45th day had a significant immediate increase in all MUFAs, PUFAs (Table 2) and total MUFAs, PUFAs and UFAs (Figures 2(b), 2(c) and $2(\mathrm{~d})$ ), leading to constant higher values compared to the control at the end of the storage period. On the other hand, the results showed that treatment at any time of interruption during storage did not result in immediate changes in the concentration of SFAs (Table 2) and the membrane saturation index (Figure 2(a)), except for a significant reduction in the indices on the 45th day. It was concluded that the statistically higher levels of UFAs and the unsaturation rates recorded at the end of the cold-warm-cold period could be mainly independent of an instant increase in SFAs in response to warming as a mandatory prerequisite. It could well be associated to the warm-induced mechanisms responsible for protecting UFAs at chilling temperatures. The warming on the 45th day led to an immediate and statistical increase in all UFAs, and a decrease in all SFAs and MDA content simultaneously (Table 2), indicating the possibility of a direct impact of treatment as an increase in UFAs, UFAs/SFAs ratio and a reduction in the peroxidation rate of UFAs. It means that the desaturation of SFAs could be a direct result of warming. This finding contrasts with the previous suggestions that the desaturation of SFAs is triggered by the return of the treated fruit to low temperatures $[6,7$, 10]. The activity of LOX and PLD enzymes as a direct effect of warming may also be likely to decrease. To be proved, this claim needs to be studied.

4.3. PAs Modifications. Based on some of the scientific evidence, the protective role of PAs in alleviating different types of stress in plants has been proposed. Reducing endogenous polyamines by applying their biosynthesis inhibitors [32-34] or by using polyamine biosynthesis mutants $[35,36]$ has been shown to result in increased sensitivity to stress and increased injury to affected tissues. Moreover, exogenous application of polyamines before or during stress [33, 37-40] could lead to an increase in their endogenous content, leading to a reduction in stress-related injuries to varying degrees, depending on a number of factors, such as individual polyamines, plant species or cultivars, type of stress and its duration and intensity [41].

The relationship between $\mathrm{CI}$ and damage to the membranes has been proven [5]. On the one hand, it has been suggested that PAs, due to their antioxidant activity, are potential for membrane binding via interactions with phospholipids [12, 42] and triggering enzymatic antioxidant activities [41, 43-45] could be responsible for lower changes in membrane fluidity and solute leakage [13], and play an important protective role in the safety of membranes under conditions of stress [14]. On the other hand, PAs rise concomitantly with CI incidence has been reported in chillingsensitive horticultural crops [46], but it remains unclear whether PAs rise is due to chilling stress or a defensive mechanism against CI [47]. For example, increases in the concentration of Put in conjunction with $\mathrm{CI}$ incidence for lemon, orange, lime, grapefruit, pepper, zucchini, and pepino fruit have been detected [48-52]. Moreover, it has been reported that IW promotes the production of PAs in treated tissues during the warming phase [11]. It was therefore of great interest for the authors to explore possible associations between the incidence of $\mathrm{CI}$, natural changes in endogenous PAs and their modifications in response to IW treatment of pomegranate fruit as a sensitive commodity.

Expression of PA biosynthetic genes under different stresses could be regulated in a disparate manner, including 
immediate induction with continuous increase or minor changes during stress periods, or induction only in response to certain stress periods [53-56]. In addition, different cultivars of the same species might also have different patterns of PAs under stress [41]. The endogenous Spm in the control fruit was significantly increased during the first month of cold storage (Figure 3(c)). This could be related to the activation of the PA biosynthesis pathway as part of the hypothesized ability of the 'Rabab-e-Neyriz' fruit to acclimate to stress. By increasing the internal content of Spd alongside the advancement in storage time (Figure 3(b)), it was concluded that Spd could play a more prominent role in alleviating the incidence of CI by extending the exposure time to chilling temperature.

Existing literature shows that postharvest techniques associated with high levels of PAs reduce CI in many sensitive horticultural commodities. For example, exogenous prestorage applications of PAs could decrease CI in commodities such as apple [57], zucchini [58], and mango [59, 60]. Likewise, pomegranate pre-storage treatment by Put or Spd significantly reduced the incidence of $\mathrm{CI}$ at chilling temperature; this effect was associated with enhanced endogenous PAs [47]. In addition to IW, the pre-storage hot water dip is known as the main method for postharvest heat treatment of horticultural commodities, which could reduce the incidence of CI associated with rises in endogenous PAs in sensitive crops [48, 61-66]. Accordingly, by prestorage hot water dip (at $45^{\circ} \mathrm{C}$ for $4 \mathrm{~min}$ ), Mirdehghan et al. [21] reported a reduction in CI and an increase in PAs in the peel of the pomegranate with such a value were always higher than in control fruit, even more than that measured at harvest. One notable finding was an instantly and statistically enhanced biosynthesis of Put and Spm in fruit treated during the first month of storage compared to control or later treated fruit (Figures 3(a) and 3(c)). In contrast to the control fruit, in the case of fruit treated on the 15th or 25th day, Spm increased steadily and significantly until the end of the storage period (Figure 3(c)). It was concluded that the rate of immediate increase and the final content of Spm in response to treatment was time-dependent and that the warming treatment was assumed to have a synergistic effect with the inherent potential of Spm biosynthesis in the fruit peel. On the one hand, only fruit treated during the first month of storage had significantly higher final Spm content than the control fruit (Figure 3(c)). On the other hand, postponing the warming treatment to more than one month of cold storage significantly lowered the rate of treatment effect on Put biosynthesis and its final value (Figure 3(a)). These findings could emphasize the importance of performing IW treatment at the right time during storage to achieve optimum performance in extending the shelf life of the treated fruit. By warming on or after the 25th day, Spd was also immediately and significantly increased, resulting in statistically higher levels both at interruption dates and at the end of the storage period in the treated fruit compared to the control fruit (Figure 3(b)). As the storage period increased, the content of Put decreased significantly in the control fruit. Furthermore, the different time-treated fruit had a final Put content lower than that recorded after harvest (Figure 3(a)). Accumulation of Put is a general reaction to stress [43], although it could be converted into Spd via spermidine synthase (SPDS, EC 2.5.1.16) [41]. It was likely that part of the continuous decrease in the content of Put in the peel of cold-stored fruit was due to the conversion to Spd. In the same way, it could be assumed that part of the increased content of Put in the treated fruit has also been transformed into Spd, with a higher rate of transformation coinciding with the progress in storage time. This hypothesized mechanism could contribute to the significantly higher levels of Spd detected in fruit treated on or after the 25th day compared to control fruit both at interruption dates and at the end of storage time.

As stated earlier, it was established from the other part of our research [17] that IW, as a single cold-warm-cold cycle, could have beneficial effects on the cold storage of 'Rabab-eNeyriz' pomegranate by inducing enzymatic and nonenzymatic antioxidant reactions in the fruit peel. It was concluded that maintaining higher levels of antioxidant activity is likely to be responsible for reducing lipid peroxidation following warming. It was founded that fruit treated for up to 35 days had significantly higher final activity of superoxide dismutase (SOD), peroxidase (POD), and ascorbate peroxidase (APX) than controls at the end of storage, with earlier warming resulting in higher activity. Furthermore, peel browning was not related to POD activity and this enzyme had only a beneficial antioxidant function. By investigating the mode of change in the content of 13 phenolic acids (as non-enzymatic antioxidants), it was also founded that the total phenolic content of the fruit treated at any time of interruption was statistically higher compared to the control, with a value higher than the time of harvest for the fruit treated during the first month of cold storage. In addition to being an important protective mechanism against CI incidence in fruit, higher total phenolic content can be regarded as an indicator of natural antioxidant sources available in the food industry.

On the basis of the overall findings of our research, it can be asserted that a single warming period at the right time during cold storage of pomegranate (before irreversible chilling damage occurs) triggers multiple mechanisms and physiological responses in fruit peel which are significantly responsible for alleviating the severity of chilling damage to this valuable horticultural commodity.

\section{Conclusions}

Using one cycle of IW by warming the cold-stored pomegranate fruit on the 15th day of storage led to an immediate and significant increase in the endogenous content of Spm and Put, followed by a continuous increase in the level of Spm and a higher level of Put up to the end of storage for treated fruit compared to control fruit. Furthermore, the cell membrane integrity index remained unchanged for the treated fruit until the end of the storage period. It was concluded that warming was likely to induce the protective mechanisms responsible for preserving UFAs from peroxidation, including modifications to endogenous PAs as membrane safety agents. The beneficial effect of the treatment was adversely affected by postponing during storage. Our findings could be crucial for industrial IW applications. It is highly recommended that the efficacy of a single warming 
period during cold storage in maintaining the postharvest quality of other perishable horticultural crops with beneficial effects on human health be evaluated. It is predictable that the use of this safe and nonchemical postharvest treatment will result in a longer period of time for consumers to have access to high-quality, health-promoting horticultural crops for use.

\section{Data Availability}

All data have been placed in the manuscript.

\section{Conflicts of Interest}

The authors declare that they have no conflict of interest.

\section{References}

[1] S. Al-Rehman, “Chapter 27,” Al-Quranno. 55, p. 534.

[2] S. Akhtar, T. Ismail, D. Fraternale, and P. Sestili, "Pomegranate peel and peel extracts: chemistry and food features," Food Chemistry, vol. 174, pp. 417-425, 2015.

[3] P. Biswas, A. R. East, E. W. Hewett, and J. A. Heyes, "Intermittent warming in alleviating chilling injury-a potential technique with commercial constraint," Food and Bioprocess Technology, vol. 9, pp. 1-15, 2016.

[4] R. A. Kluge, M. L. L. Jomori, A. P. Jacomino, M. C. D. Vitti, and M. Padula, "Intermittent warming in 'Tahiti' lime treated with an ethylene inhibitor," Postharvest Biology and Technology, vol. 29, no. 2, pp. 195-203, 2003.

[5] D. Valero and M. Serrano, "Heat treatments," in Postharvest Biology and Technology for Preserving Fruit Quality, D. Valero and M. Serrano, Eds., pp. 90-108, CRC Press, Taylor and Francis, Boca Raton, USA, 2010.

[6] C. Y. Wang, "Physiological and biochemical responses of plants to chilling stress," HortScience, vol. 17, pp. 173-186, 1982.

[7] C. Y. Wang, "Chilling injury of tropical horticultural commodities," HortScience, vol. 29, no. 9, pp. 986-988, 1994.

[8] L. Taghipour, M. Rahemi, and P. Assar, "Determining the physiochemical changes and time of chilling injury incidence during cold storage of pomegranate fruit," Journal of Agricultural Sciences, Belgrade, vol. 60, no. 4, pp. 465-476, 2015.

[9] L. Sevillano, M. T. Sanchez-Ballesta, F. Romojaro, and F. B. Flores, "Physiological, hormonal and molecular mechanisms regulating chilling injury in horticultural species. Postharvest technologies applied to reduce its impact," Journal of the Science of Food and Agriculture, vol. 89, no. 4, pp. 555-573, 2009.

[10] C. Y. Wang, "Approaches to reduce chilling injury of fruits and vegetables," in Horticultural reviews, volume 15, J. Janick, Ed., pp. 63-95, Wiley, New York, USA, 1993.

[11] C. Y. Wang and J. E. Baker, "Effects of two free radical scavengers and intermittent warming on chilling injury and polar lipid composition of cucumber and sweet pepper fruits," Plant and Cell Physiology, vol. 20, no. 1, pp. 243-251, 1979.

[12] S. S. Hussain, M. Ali, M. Ahmad, and K. H. M. Siddique, "Polyamines: natural and engineered abiotic and biotic stress tolerance in plants," Biotechnology Advances, vol. 29, no. 3, pp. 300-311, 2011.

[13] M. Serrano, D. Martinez-Romero, F. Guillen, and D. Valero, "Effects of exogenous putrescine on improving shelf life of four plum cultivars," Postharvest Biology and Technology, vol. 30, no. 3, pp. 259-271, 2003.

[14] M. D. Groppa and M. P. Benavides, "Polyamines and abiotic stress: recent advances," Amino Acids, vol. 34, pp. 35-45, 2008.

[15] G. F. Kramer and C. Y. Wang, "Reduction of chilling injury in zucchini squash by temperature management," HortScience, vol. 24, pp. 995-996, 1989.

[16] C. Y. Wang, "Alleviation of chilling injury of horticultural crops," in Chilling Injury of Horticultural Crops, C. Y. Wang, Ed., pp. 281-301, CRC Press, Boca Raton, USA, 1990.

[17] L. Taghipour, M. Rahemi, P. Assar, S. H. Mirdehghan, and A. Ramezanian, "Intermittent warming as an efficient postharvest treatment affects the enzymatic and non-enzymatic responses of pomegranate during cold storage," Journal of Food Measurement and Characterization, vol. 15, pp. 12-22, 2020.

[18] R. L. Heath and L. Packer, "Photoperoxidation in isolated chloroplasts: I. kinetics and stoichiometry of fatty acid peroxidation," Archives of Biochemistry and Biophysics, vol. 125, no. 1, pp. 189-198, 1968.

[19] M. Sayyari, M. Babalar, S. Kalantari, M. Serrano, and D. Valero, "Effect of salicylic acid treatment on reducing chilling injury in stored pomegranates," Postharvest Biology and Technology, vol. 53, no. 3, pp. 152-154, 2009.

[20] H. Rui, S. Cao, H. Shang, P. Jin, K. Wang, and Y. Zheng, "Effects of heat treatment on internal browning and membrane fatty acid in loquat fruit in response to chilling stress," Journal of the Science of Food and Agriculture, vol. 90, pp. 1557-1561, 2010.

[21] S. H. Mirdehghan, M. Rahemi, D. Martínez-Romero et al., "Reduction of pomegranate chilling injury during storage after heat treatment: role of polyamines," Postharvest Biology and Technology, vol. 44, no. 1, pp. 19-25, 2007.

[22] A. G. Marangoni, T. Palma, and D. W. Stanley, "Membrane effects in postharvest physiology," Postharvest Biology and Technology, vol. 7, no. 3, pp. 193-217, 1996.

[23] T. Sakamoto and N. Murata, "Regulation of the desaturation of fatty acids and its role in tolerance to cold and salt stress," Current Opinion in Microbiology, vol. 5, no. 2, pp. 208-210, 2002.

[24] M. L. Hernández, M. N. Padilla, M. D. Sicardo, M. Mancha, and J. M. Martínez Rivas, "Effect of different environmental stresses on the expression of oleate desaturase genes and fatty acid composition in olive fruit," Phytochemistry, vol. 72, pp. 178-187, 2011.

[25] D. A. Los and N. Murata, "Membrane fluidity and its roles in the perception of environmental signals," Biochimica et Biophysica Acta (BBA)-biomembranes, vol. 1666, pp. 142-157, 2004.

[26] C. Yu, H. S. Wang, S. Yang, X. F. Tang, M. Duan, and Q. W. Meng, "Overexpression of endoplasmic reticulum omega-3 fatty acid desaturase gene improves chilling tolerance in tomato," Plant Physiology and Biochemistry, vol. 47, pp. 1102-1112, 2009.

[27] S. Cao, Z. Yang, Y. Cai, and Y. Zheng, "Fatty acid composition and antioxidant system in relation to susceptibility of loquat fruit to chilling injury," Food Chemistry, vol. 127, no. 4, pp. 1777-1783, 2011.

[28] R. G. Pinhero, G. Paliyath, R. Y. Yada, and D. P. Murr, "Modulation of phospholipase D and lipoxygenase activities during chilling. Relation to chilling tolerance of maize seedlings," 
Plant Physiology and Biochemistry, vol. 36, no. 3, pp. 213-224, 1998.

[29] M. S. Aghdam and S. Bodbodak, "Postharvest heat treatment for mitigation of chilling injury in fruits and vegetables," Food and Bioprocess Technology, vol. 7, no. 1, pp. 37-53, 2014.

[30] M. D. C. Antunes and E. M. Sfakiotakis, "Changes in fatty acid composition and electrolyte leakage of 'Hayward' kiwifruit during storage at different temperatures," Food Chemistry, vol. 110, no. 4, pp. 891-896, 2008.

[31] C. M. Rivera and D. Penner, "Rapid changes in soybean root membrane lipids with altered temperature," Phytochemistry, vol. 17, no. 8, pp. 1269-1272, 1978.

[32] Z. Y. Li and S. Y. Chen, "Differential accumulation of Sadenosylmethionine decarboxylase transcript in rice seedlings in response to salt and drought stresses," Theoretical and Applied Genetics, vol. 100, pp. 782-788, 2000.

[33] E. Navakouidis, C. Lütz, C. Langebartels, U. Lütz-Meindl, and K. Kotzabasis, "Ozone impact on the photosynthetic apparatus and the protective role of polyamines," Biochimica et Biophysica Acta, vol. 1621, pp. 160-169, 2003.

[34] A. J. Rowland-Bamford, A. M. Borland, P. J. Lea, and T. A. Mansfield, "The role of arginine decarboxylase in modulating the sensitivity of barley to ozone," Environmental Pollution, vol. 61, no. 2, pp. 95-106, 1989.

[35] V. Kasinathan and A. Wingler, "Effect of reduced arginine decarboxylase activity on salt tolerance and on polyamine formation during salt stress in Arabidopsis thaliana," Physiologia Plantarum, vol. 121, no. 1, pp. 101-107, 2004.

[36] K. Urano, Y. Yoshiba, T. Nanjo et al., "Arabidopsis stressinducible gene for arginine decarboxylase AtADC2 is required for accumulation of putrescine in salt tolerance," Biochemical and Biophysical Research Communications, vol. 313, no. 2, pp. 369-375, 2004.

[37] A. Borrell, T. Bestford, T. Altabella, C. Masgrau, and A. F. Tiburcio, "Regulation of arginine decarboxylase by spermine in osmotically-stressed oat leaves," Physiologia Plantarum, vol. 98, no. 1, pp. 105-110, 1996.

[38] V. Velikova, I. Yordanov, and A. Edreva, "Oxidative stress and some antioxidant systems in acid rain-treated bean plants: protective role of exogenous polyamines," Plant Science, vol. 151, pp. 59-66, 2000.

[39] V. B. Velikova, I. T. Yordanov, K. M. Georgieva, T. D. Tsonev, and V. Goltsev, "Effects of exogenous polyamines applied separately and in combination with simulated acid rain on functional activity of photosynthetic apparatus," Journal of Plant Physiology, vol. 153, pp. 299-307, 1998.

[40] X. Wang, G. Shi, Q. Xu, and J. Hu, "Exogenous polyamines enhance copper tolerance of Nymphoides peltatum," Journal of Plant Physiology, vol. 164, no. 8, pp. 1062-1070, 2006.

[41] J. H. Liu, H. Kitashiba, J. Wang, Y. Ban, and T. Moriguchi, "Polyamines and their ability to provide environmental stress tolerance to plants," Plant Biotechnology, vol. 24, no. 1, pp. 117-126, 2007.

[42] W. Shen, K. Nada, and S. Tachibana, "Involvement of polyamines in the chilling tolerance of cucumber cultivars," Plant Physiology, vol. 124, no. 1, pp. 431-439, 2000.

[43] M. Koushesh Saba, K. Arzani, and M. Barzegar, "Postharvest polyamine application alleviates chilling injury and affects apricot storage ability," Journal of Agricultural and Food Chemistry, vol. 60, pp. 8947-8953, 2012.
[44] L. Öztürk and Y. Demir, "Effects of putrescine and ethephon on some oxidative stress enzyme activities and proline content in salt stressed spinach leaves," Plant Growth Regulation, vol. 40, pp. 89-95, 2003.

[45] S. Verma and S. N. Mishra, "Putrescine alleviation of growth in salt stressed Brassica juncea by inducing antioxidative defense system," Journal of Plant Physiology, vol. 162, no. 6, pp. 669677, 2005.

[46] A. Bouchereau, A. Aziz, F. Larher, and J. Martin-Tanguy, "Polyamines and environmental challenges: recent developments," Plant Science, vol. 140, no. 2, pp. 103-125, 1999.

[47] S. H. Mirdehghan, M. Rahemi, S. Castillo, D. MartínezRomero, M. Serrano, and D. Valero, "Pre-storage application of polyamines by pressure or immersion improves shelf-life of pomegranate stored at chilling temperature by increasing endogenous polyamine levels," Postharvest Biology and Technology, vol. 44, no. 1, pp. 26-33, 2007.

[48] G. A. González-Aguilar, L. Gayosso, R. Cruz, J. Fortiz, R. Báez, and C. I. Wang, "Polyamines induced by hot water treatments reduce chilling injury and decay in pepper fruit," Postharvest Biology and Technology, vol. 18, no. 1, pp. 19-26, 2000.

[49] D. Martínez-Romero, M. Serrano, and D. Valero, "Physiological changes in Pepino (Solanum muricatum Ait) fruit stored at chilling and non-chilling temperatures," Postharvest Biology and Technology, vol. 30, no. 2, pp. 177-186, 2003.

[50] M. Serrano, M. C. Martínez-Madrid, G. Martínez, F. Riquelme, M. T. Petrel, and F. Romojaro, "Review: role of polyamines in chilling injury of fruit and vegetables," Food Science and Technology International, vol. 2, no. 4, pp. 195-199, 1996.

[51] M. Serrano, M. C. Martínez-Madrid, M. T. Pretel, F. Riquelme, and F. Romojaro, "Modified atmosphere packaging minimizes increases in putrescine and abscisic acid levels caused by chilling injury in pepper fruit," Journal of Agricultural and Food Chemistry, vol. 45, no. 5, pp. 1668-1672, 1997.

[52] M. Serrano, M. T. Pretel, M. C. Martínez-Madrid, F. Romojaro, and F. Riquelme, " $\mathrm{CO}_{2}$ treatment of zucchini squash reduces chilling-induced physiological changes," Journal of Agricultural and Food Chemistry, vol. 46, no. 7, pp. 2465-2468, 1998.

[53] M. K. Chattopadhyay, S. Gupta, D. N. Sengupta, and B. Ghosh, "Expression of arginine decarboxylase in seedlings of indica rice (Oryza sativa L.) cultivars as affected by salinity stress," Plant Molecular Biology, vol. 34, pp. 477-483, 1997.

[54] Y. J. Hao, H. Kitashiba, C. Honda, K. Nada, and T. Moriguchi, "Expression of arginine decarboxylase and ornithine decarboxylase genes in apple cells and stressed shoots," Journal of Experimental Botany, vol. 56, pp. 1105-1115, 2005.

[55] Z. Y. Li and S. Y. Chen, "Isolation and characterization of a salt- and drought-inducible gene for S-adenosylmethionine decarboxylase from wheat (Triticum aestivum L.)," Journal of Plant Physiology, vol. 156, no. 3, pp. 386-393, 2000.

[56] J. H. Liu, K. Nada, C. Honda et al., "Polyamine biosynthesis of apple callus under salt stress: importance of arginine decarboxylase pathway in stress response," Journal of Experimental Botany, vol. 57, no. 11, pp. 2589-2599, 2006.

[57] G. F. Kramer, C. Y. Wang, and W. S. Conway, "Inhibition of softening by polyamine application in 'Golden delicious' and 'McIntosh' apples," Journal of the American Society for Horticultural Science, vol. 116, no. 5, pp. 813-817, 1991.

[58] M. A. Martínez-Téllez, M. G. Ramos-Clamont, A. A. Gardena, and I. Vargas-Arispuro, "Effect of infiltrated 
polyamines on polygalacturonase activity and chilling injury responses in zucchini squash (Cucurbita pepo L)," Biochemical and Biophysical Research Communications, vol. 295, no. 1, pp. 98-101, 2002.

[59] S. Kondo, W. Ponrod, and S. Sutthiwal, "Polyamines in developing mangosteens and their relationship to postharvest chilling injury," Journal of the Japanese Society for Horticultural Science, vol. 72, no. 4, pp. 318-320, 2003.

[60] S. Nair and Z. Singh, "Chilling injury in mango fruit in relation to biosynthesis of free polyamines," The Journal of Horticultural Science and Biotechnology, vol. 79, no. 4, pp. 515-522, 2004.

[61] J. C. Abu-Kpawoh, Y. E. Xi, Y. Z. Zhang, and Y. F. Jin, "Polyamine accumulation following hot-water dips influences chilling injury and decay in 'friar' plum fruit," Journal of Food Science, vol. 67, no. 7, pp. 2649-2653, 2002.

[62] M. Ghasemnezhad, K. Marsh, R. Shilton, M. Babalar, and A. Woolf, "Effect of hot water treatments on chilling injury and heat damage in 'Satsuma' mandarins: antioxidant enzymes and vacuolar ATPase, and pyrophosphatase," Postharvest Biology and Technology, vol. 48, no. 3, pp. 364-371, 2008.

[63] G. A. González-Aguilar, L. Zacarías, M. A. Pérez-Amador, J. Carbonell, and M. T. Lafuente, "Polyamine content and chilling susceptibility are affected by seasonal changes in temperature and by conditioning temperature in cold-stored 'fortune' mandarin fruit," Physiologia Plantarum, vol. 108, no. 2, pp. 140-146, 2000.

[64] Q. Ma, J. Sue, D. J. Huber et al., "Effect of hot water treatments on chilling injury and expression of a new C-repeat binding factor $(C B F)$ in 'Hongyang' kiwifruit during low temperature storage," Postharvest Biology and Technology, vol. 97, pp. 102-110, 2014.

[65] J. Y. Wang, "Combined treatment of heat shock and lowtemperature conditioning reduces chilling injury in zucchini squash," Postharvest Biology and Technology, vol. 4, pp. 6573, 1994.

[66] C. Xu, Z. Jin, and S. Yang, "Polyamines induced by heat treatment before cold-storage reduce mealiness and decay in peach fruit," The Journal of Horticultural Science and Biotechnology, vol. 5, pp. 557-560, 2005. 